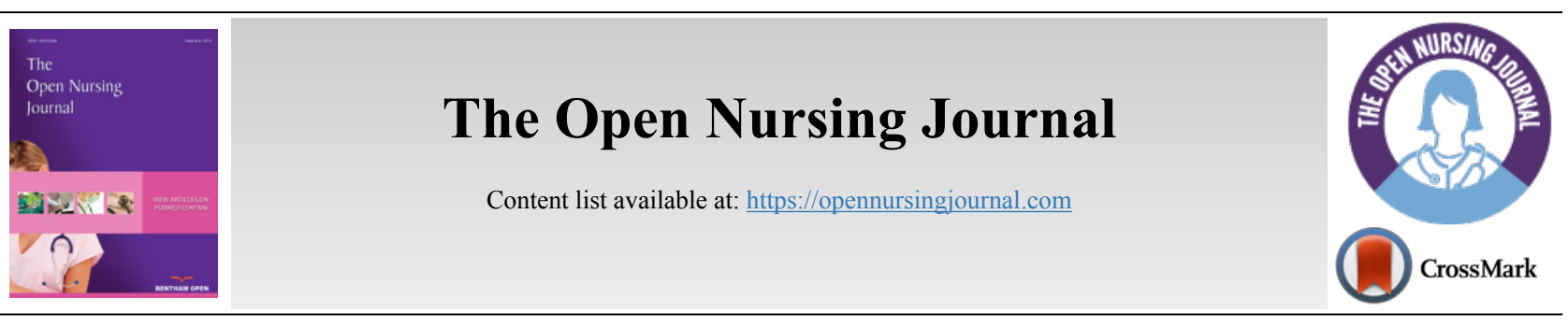

RESEARCH ARTICLE

\title{
The Nurse as an Information Broker for Children with Terminal Illness: A Qualitative Study
}

\author{
Fanny Adistie ${ }^{1, *}$, Henny S. Mediani ${ }^{1}$, Valentina B.M. Lumbantobing ${ }^{2}$, Nenden N.A. Maryam ${ }^{1}$ and Sri Hendrawati ${ }^{1}$ \\ ${ }^{I}$ Pediatric Nursing Department, Faculty of Nursing, Universitas Padjadjaran, Bandung, Indonesia \\ ${ }^{2}$ Fundamental Nursing Department, Faculty of Nursing, Universitas Padjadjaran, Bandung, Indonesia
}

\begin{abstract}
:
Background:

Providing care for children with a terminal illness is a great challenge for nurses and might be very complex. Several roles can be performed while providing nursing care.

Objective:

The aim of this study was to identify the roles of nurses in providing nursing care to children with terminal illness and explore the nurse's perspective on how they perform their role in caring for children with terminal illness.

\section{Methods:}

This research was conducted qualitatively with a content analysis approach. In-depth interviews with 8 nurses and focus group discussion with 7 nurses were the data collection methods used in this study. The sampling technique in this research is purposive sampling with inclusion criteria for nurses who were willing to participate in this research with a minimum education of diploma degree in nursing, and having at least 3 years of working experience in the pediatric ward.

Results:

Based on the nurses' perspectives, their role as a communicator, counselor, collaborator, advocator, educator, and also as care provider make them an information broker for children with terminal illnesses and their families.

\section{Conclusion:}

In conclusion, while performing the roles, nurses must have good communication skills and knowledge related to the condition of the child as well as the ability to work with other healthcare teams with the purpose of providing holistic and comprehensive care for children with a terminal illness.
\end{abstract}

Keywords: Children, Information broker, Nurse's role, Terminal illness, Communicator, Counselor, Collaborator, Advocator, Educator.

\begin{tabular}{l|l|l|r} 
Article History & Received: July 06, 2020 & Revised: November 23, 2020 & Accepted: November 30, 2020
\end{tabular}

\section{INTRODUCTION}

Nurses face a great challenge while providing the best care for children with terminal illness and families to fulfill their physical, psychological, spiritual, and emotional needs in the course of an uncertain and even long-lasting illness [1]. Nurses may be the first to meet with children and families and spend more time than other health workers [2]. End-of-life care for pediatric is holistic care intending to improve the quality of life

\footnotetext{
"Address correspondence to this author at Department of Pediatric Nursing, Faculty of Nursing, Universitas Padjadjaran, Bandung, Indonesia; Tel: +6281220827968; E-mail: fanny.adistie@unpad.ac.id
}

despite the prognosis [3]. Although the child has been diagnosed with an incurable illness, nursing care must remain active to maintain the child's comfort as well as maintain the quality of life of the child in order to grow as optimally as possible.

Nurses play an important role in caring for the child who is dying and his/her family. Providing care for a dying child is a multidisciplinary and family-centered process. Nurses should acknowledge the physiological, emotional, and spiritual needs of the child and the family during this difficult time. Children show different responses to the imminent process of dying and 
death, depending on their level of development [2].

According to American Nurses Association (ANA) (2016), nurses are obliged to provide comprehensive and compassionate care for dying children, recognize when the child is about to take his/her last breath and deliver the information to the family [4]. The primary responsibility of a nurse is to provide nursing care to children and families. Nurses should cooperate with family members to identify their goals and needs, and plan the most appropriate interventions to address the problem [1].

Nurses perform several roles when they provide care to clients and often carry out these roles concurrently, not exclusively [5]. The roles of nurses, among others, are as an advocate, health care provider, communicator, member of the team, educator and leader [6]. Providing interventions to reduce suffering and improve quality of life at each and every stage of the illness is the focus of palliative care in children and a multidisciplinary team is the most effective for treatments like this [7]. In a team, nurses enact an essential role by recognizing symptoms, coordinating care, and facilitating communication [7].

Providing end-of-life care for pediatric patients and their families is a privilege and also a challenge for nurses. Helping patients at the end of their life enables nurses to apply many of the technical skills and mental health skills learned throughout the nursing program [6]. A nurse can help parents by providing detailed information about what will happen if the supportive equipment is removed, ensuring that the pain medication given is appropriate for relieving pain during the dying process, and allowing parents to be with their child and talk to him/her before the release of the device. It is important for nurses to attempt to control the environment by providing privacy, asking them if they want to listen to the music, dim the lights and turn down the sound of the monitors, and organize the religious or cultural rituals that the family might want to do [1].

Nurses often perform multiple roles simultaneously. Similarly, when a nurse cares for a child with a terminal illness , the roles needed at any given time depend on the patient's needs and a particular situation [5]. While caring for a child with a terminal illness, nurses go through many experiences; one of them is related to decision-making. Making end-of-life decisions often involves ethical dilemmas for children, families and other health care teams [2]. The vagueness of the role of health professionals can be a difficult factor in decision making at the patient's end of life [8]. Furthermore, collaboration must be carried out by nurses with other health care teams to ensure optimal management of symptoms and to provide support for patients and families [4]. This study was conducted to identify the roles of nurses in providing nursing care to children with a terminal illness and explore the nurses' perspectives on how they perform their role in caring for terminally ill children.

\section{MATERIALS AND METHODS}

\subsection{Study Design}

A qualitative research design with a content analysis approach is used in this study to explore the nurses' perspectives on how they perform their role in caring for children with terminal illnesses.

\subsection{Setting and Participants}

Purposive sampling is a sampling technique used in this study. Focusing on certain attributes of a population of concern will provide the best answers to research questions which is the main objective of this technique [9]. Nurses with a minimum education of diploma degree in nursing, willing to be involved and participate, and have experience of at least 3 years of working in the pediatric ward, were eligible for this research. In this hospital, there is a trend for nurse rotation; hence by determining the years of experience of care for children, the quality of nursing can be assessed. Clinical nursing expertise relates to the nurses' education level and years of experience [10]. Fifteen nurses participated in this study who were representatives of the pediatric surgical ward, the internal disease pediatric ward, the pediatric intensive care unit (PICU), and the neonatal intensive care unit (NICU).

\subsection{Ethical Consideration}

This study adheres to ethical principles of beneficence, autonomy, justice, do no harm and protection for the rights of individuals involved in this study and approved by the ethical committee on health research RSUP Dr. Hasan Sadikin Bandung with approval number LB.04.01/A05/EC/191/VII/ 2017.

\subsection{Data Collection}

In this study, qualitative research data were based on information obtained from the participants regarding how nurses performed their role in caring for children with a terminal illness. Once ethical approval was obtained from the ethics committee and the researcher obtained permission, respondents were sought in accordance with the inclusion criteria and informed consent was taken.

Focus group discussion (FGD) and in-depth interviews were conducted from August to November 2017. FGD was conducted for $60 \mathrm{~min}$, and in-depth interviews with nurses were performed for 30-60 min. Through this technique, researchers gained information about how nurses performed their roles in providing care for children with a terminal illness. Qualitative research instruments were used in this study, with researchers as the main instrument. Interview results were recorded and the next process was transcribing the data obtained from the interviews. A chronological note was made to describe any extraordinary event during the interview.

\subsection{Data Analysis}

Content analysis was used to conduct data analysis in this study. Data collection was carried out simultaneously with data analysis. The information obtained was arranged into the meaning unit to be coded and categories were created based on the tendency and patterns of words used in connection and also structural discourse. The codes were then grouped and a general description of the research topic was written. The last phase reports the analysis process and presents the results [1113]. 
The validity of this study is based on several criteria, such as credibility, transferability, dependability, and confirmability. The data collected were relayed back to the respondents to get the views of the respondents regarding the interpretation of the data. The respondents were representative of various pediatric wards. During the data collection process, the data analysis included researchers outside the team who examined the process and also examined the interpretation of the data and the conclusions whether it was supported by the data. The research team conducted a review of the data independently, then held discussions on the findings and reached an agreement [14 - 16].

\section{RESULTS}

Fifteen nurses participated with a minimum bachelor's degree, aged 25-45 years and having the clinical nursing experience of 5-20 years for pediatric patients (Table 1).

The results of the data analysis propose that the nurses perform the following roles in providing care for children with a terminal illness, and while performing these roles, they play the role of an information broker for a patient/family and the physician and also for the other health care providers.

Table 1. An analysis schedule.

\begin{tabular}{|c|c|c|c|}
\hline Meaning Unit & Subcategories & Categories & $\begin{array}{c}\text { Main } \\
\text { Category }\end{array}$ \\
\hline $\begin{array}{l}\text { Sometimes doctors give only a cursory explanation, we repeat it again } \\
\text { (R1) }\end{array}$ & $\begin{array}{c}\text { Repeating the explanation that the doctor has } \\
\text { submitted until the family can understand and } \\
\text { accept the condition of the child. }\end{array}$ & \multirow[t]{4}{*}{ Communicator } & \multirow[t]{8}{*}{$\begin{array}{l}\text { Nurse as an } \\
\text { information } \\
\text { broker }\end{array}$} \\
\hline $\begin{array}{l}\text { As a communicator between the doctor and the mother, we help to } \\
\text { convey the opinions of the mother and also the child. We help to } \\
\text { explain (R10) }\end{array}$ & $\begin{array}{l}\text { Clarifying the information that has already } \\
\text { been submitted by the doctor. }\end{array}$ & & \\
\hline \multirow[t]{2}{*}{$\begin{array}{l}\text { So, we explain also to the patient's family. Translating back what the } \\
\text { doctors say, with the language they can understand (R12) }\end{array}$} & $\begin{array}{l}\text { Becoming a supporting factor in the } \\
\text { explanation that has already been delivered } \\
\text { by the doctor. }\end{array}$ & & \\
\hline & $\begin{array}{l}\text { Translating what the doctor has explained in } \\
\text { a language that is easily understood by } \\
\text { parents and children. }\end{array}$ & & \\
\hline \multirow[t]{2}{*}{$\begin{array}{l}\text { Sometimes the nurse goes with the doctor while explaining the terminal } \\
\text { patient, the nurse is with the doctor to help to calm the family (R15). }\end{array}$} & $\begin{array}{l}\text { Nurses overcome parents' anxiety by } \\
\text { providing information }\end{array}$ & \multirow[t]{4}{*}{ Counselor. } & \\
\hline & $\begin{array}{l}\text { Nurses help to calm the family when the } \\
\text { condition of the terminal disease of their } \\
\text { child is communicated to them in detail. }\end{array}$ & & \\
\hline \multirow{2}{*}{$\begin{array}{l}\text { There are times when the doctors are more theoretical, not touching the } \\
\text { heart. We as a nurse should be more touching, even though speaking } \\
\text { overtly, as it is, but the family understands. We clarify, repeat, and ask } \\
\text { again whether the family has already understood or not about what has } \\
\text { been said by the doctor (R14). }\end{array}$} & $\begin{array}{l}\text { Nurses provide motivation to families when } \\
\text { families receive any bad news related to the } \\
\text { condition of the child. }\end{array}$ & & \\
\hline & $\begin{array}{l}\text { Nurses communicate with empathy and } \\
\text { sympathy, ensuring family satisfaction in } \\
\text { receiving information so that the family is } \\
\text { able to accept the terminal condition of the } \\
\text { child. }\end{array}$ & & \\
\hline $\begin{array}{l}\text { This patient has cancer and we have done all the interventions and the } \\
\text { treatments, ... the treatment is only for supportive. Well, on the other } \\
\text { side, if the patient is hospitalized continuously it will cause another } \\
\text { infection, Meanwhile, if treated at home, he can sleep quite well and } \\
\text { enjoy a peaceful life (R8). }\end{array}$ & $\begin{array}{l}\text { Nurses prevent patients from being infected } \\
\text { with any infection during their stay in the } \\
\text { hospital. }\end{array}$ & \multirow[t]{3}{*}{ Collaborator } & \multirow[t]{3}{*}{$\begin{array}{l}\text { Nurse as an } \\
\text { information } \\
\text { broker. }\end{array}$} \\
\hline $\begin{array}{l}\text { If the patient should be in rehabilitation, we should communicate with } \\
\text { the doctor in charge (R10). }\end{array}$ & $\begin{array}{c}\text { Arrange nutrition and rehabilitation programs } \\
\text { for patients by communicating the patient's } \\
\text { needs to other health care teams such as other } \\
\text { nurses, doctors, nutritionists, administration, } \\
\text { and pharmacy. }\end{array}$ & & \\
\hline $\begin{array}{l}\text { Everything is related, we cannot stand alone, so in providing service, } \\
\text { we have to collaborate well with fellow nurses, doctors, nutritionists, } \\
\text { administration, and also pharmacy. We have to communicate well about } \\
\text { the needs of patients to the team (R11). }\end{array}$ & - & & \\
\hline
\end{tabular}




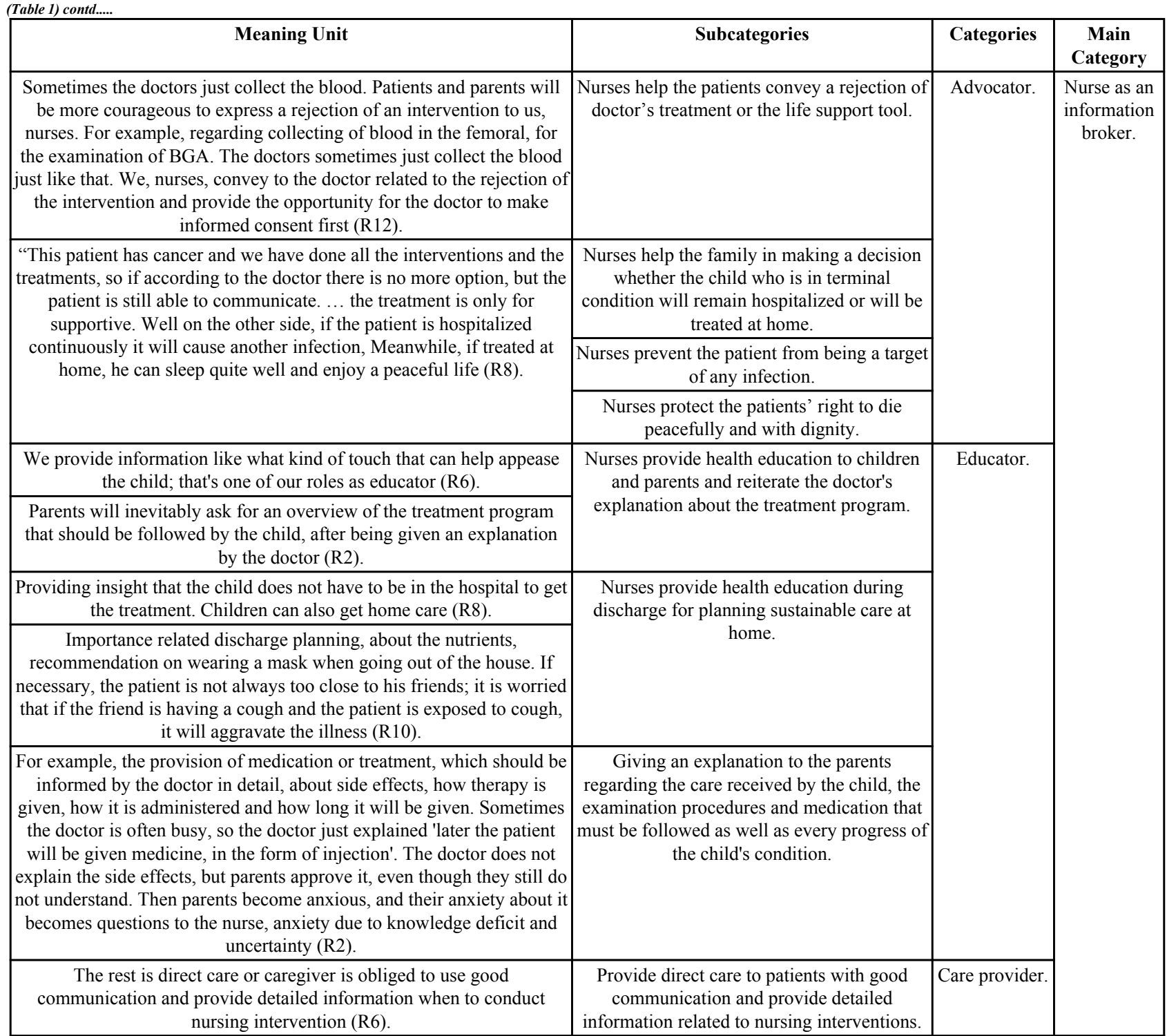

\subsection{Nurse as a Communicator}

Performing the role of a communicator, a nurse's duties include: (1) repeating the information that the doctor has communicated until the family understand and accept the condition of the child; (2) translating what the doctor has explained in a language that is easily understood by parents and children; (3) becoming a supporting factor in the explanation that has already been delivered by the doctor; and (4) clarifying the information that has already been communicated by the doctor. Some respondent statements related to these subcategories are as follows:

"Sometimes doctors give only a cursory explanation, we repeat it again" $(\mathrm{R} 1)$

"As a communicator between the doctor and the mother, we help to convey the opinions of the mother and also the child. We help to explain" (R10).

"So, we explain also to the patient's family. Translating back what the doctors say, with the language they can understand" (R12).

\subsection{Nurse as Counselor}

In this role, there are several subcategories identified, among them: (1) nurses overcome parents' anxiety by providing information; (2) nurses help to calm the family when the condition of the terminal disease of their child is communicated to them in detail; (3) nurses provide motivation to families when families receive any bad news related to the condition of the child; and (4) nurses communicate with empathy and sympathy, ensuring family satisfaction in receiving information so that the family is able to accept the terminal condition of the child. Some respondents' statements related to this subcategory are as follows:

"Sometimes the nurse goes with the doctor while explaining the terminal patient, the nurse is with the doctor to help to calm the family" (R15).

"There are times when the doctors are more theoretical, not touching the heart. We as a nurse should be more touching, even though speaking overtly, as it is, but the family understands. We clarify, repeat, and ask again whether the family has already understood or not about what has been said by the doctor (R14). 


\subsection{Nurse as a Collaborator}

In this role as a collaborator, nurses prevent patients from being infected with any infection during their stay in the hospital, arrange nutrition and rehabilitation programs for patients by communicating the patient's needs to other health care teams such as other nurses, doctors, nutritionists, administration, and pharmacy. Some respondents' statements related to this subcategory are as follows:

"This patient has cancer and we have done all the interventions and the treatments, ... the treatment is only for supportive. Well on the other side, if the patient is hospitalized continuously it will cause another infection, Meanwhile, if treated at home, he can sleep quite well and enjoy a peaceful life" (R8).

"If the patient should be in rehabilitation, we should communicate with the doctor in charge" (R10).

"Everything is related, we cannot stand alone, so in providing service, we have to collaborate well with fellow nurses, doctors, nutritionists, administration, and also pharmacy. We have to communicate well about the needs of patients to the team" (R11).

\subsection{Nurse as an Advocator}

Following are the roles of nurses based on this category: (1) nurses help the patients convey a rejection of doctor's treatment or the life support tool; (2) nurses help the family in making a decision whether the child who is in terminal condition will remain hospitalized or will be treated at home; (3) nurses prevent the patient from being a target of any infection; and (4) nurses protect the patients' right to die peacefully and with dignity. Some respondents' statements related to this subcategory are as follows:

"Sometimes the doctors just collect the blood. Patients and parents will be more courageous to express a rejection of an intervention to us, nurses. For example, regarding collecting of blood in the femoral, for the examination of BGA. The doctors sometimes just collect the blood just like that. We, nurses, convey to the doctor related to the rejection of the intervention and provide the opportunity for the doctor to make informed consent first." (R12).

"This patient has cancer and we have done all the interventions and the treatments, so if according to the doctor there is no more option, but the patient is still able to communicate. ... the treatment is only for supportive. Well on the other side, if the patient is hospitalized continuously it will cause another infection, Meanwhile, if treated at home, he can sleep quite well and enjoy a peaceful life" (R8).

\subsection{Nurse as an Educator}

In this role, nurses provide health education to children and parents and reiterate the doctor's explanation about the treatment program; nurses provide health education during discharge for planning sustainable care at home; and giving an explanation to the parents regarding the care received by the child, the examination procedures and medication that must be followed as well as every progress of the child's condition.
Some respondents' statements related to this subcategory are as follows:

"We provide information like what kind of touch that can help appease the child; that's one of our roles as educator" (R6).

"Parents will inevitably ask for an overview of the treatment program that should be followed by the child, after being given an explanation by the doctor" (R2).

"Providing insight that the child does not have to be in the hospital to get the treatment. Children can also get home care" (R8).

"Importance related discharge planning, about the nutrients, recommendation on wearing a mask when going out of the house. If necessary, the patient is not always too close to his friends; it is worried that if the friend is having a cough and the patient is exposed to cough, it will aggravate the illness" (R10).

"For example, the provision of medication or treatment, which should be informed by the doctor in detail, about side effects, how therapy is given, how it is administered and how long it will be given. Sometimes the doctor is often busy, so the doctor just explained 'later the patient will be given medicine, in the form of injection'. The doctor does not explain the side effects, but parents approve it, even though they still do not understand. Then parents become anxious, and their anxiety about it becomes questions to the nurse, anxiety due to knowledge deficit and uncertainty." (R2).

\subsection{Nurse as a Care Provider}

In this role (Fig. 1), it is identified that nurses provide direct care to patients with good communication and provide detailed information related to nursing interventions. Some respondents' statements related to this subcategory are as follows:

"The rest is direct care or caregiver is obliged to use good communication and provide detailed information when to conduct nursing intervention" (R6).

\section{DISCUSSION}

Based on the results, while performing their roles in children's life with terminal illnesses, nurses are seen as informers. As identified when a nurse acts as a communicator, he/she repeats, translates, and clarifies the explanation that has already been delivered by the doctor until the family is able to comprehend and accept the condition of the child. To perform this role, nurses must have excellent communication skills and also good knowledge of the children's medical condition [4]. In addition, as a communicator, the nurse must be capable of communicating clearly and accurately in order to meet the client's needs [5]. Effective communication is needed to foster a trustworthy relationship between children experiencing lifethreatening conditions, their parents, and the health care team because confusing or incomplete information might be distressing for the health care team and families also [17]. Nurses have a crucial role in facilitating communication among families and the health care team. Nurses, as an informer are liable to provide correct information regarding patients to doctors and family members [8]. 


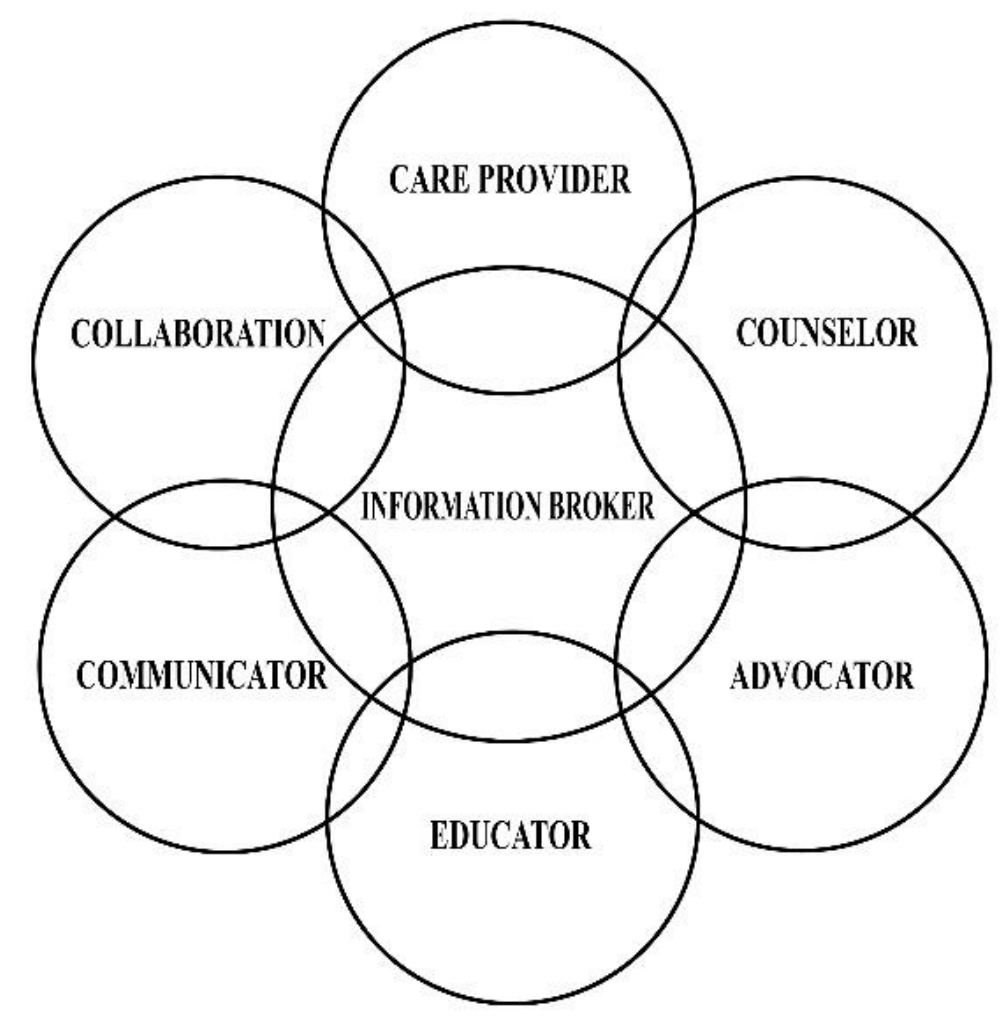

Fig. (1). Roles of nurses in providing care to children with a terminal illness.

The role of nurses as a counselor requires that they must be able to overcome anxiety in parents and appease the family. Nurses should also pay attention to communicate information with empathy so that parents accept their child's condition with positivity. It is highly demanding for nurses since they also see the patients' condition and the emotional struggles that their families experience and get emotionally connected [18]. Nurturing trust among the family and the health care team with good communication at the end of a child's life could help ensure that the child receives the best proper care [19]. Continuously providing information about the situations of dying children to their family members is also one of the roles of nurses [20]. In addition, many children with terminal conditions experience sickness for a long time. Therefore, as aninformer, nurses have to communicate honestly. While discussing complicated issues, nurses are overt to the indirect comments from child or family that express uncertainty or concerns about the direction of care and nurses have to answer the questions honestly, and if nurses do not know the answer, they have to convince the family that they will arrange a discussion with the physician $[1,21]$. What is needed for the purpose of care conversations is factual information and a nurse might say the same thing but in a different way because, as an information broker, the approach must be in congruence with the nurse as a supporter [22].

The nurse, as a collaborator, is also discussed in this study. As a collaborator, the nurse communicates the patients' needs to other health care teams. The conflict between the members of the health-care team might become a barrier in performing this role; this situation is common and might lead to moral distress among team members [23]. Effective collaboration is required because family relationships with medical staff can be affected by miscommunication, especially when the medical staff gives different opinions regarding the prognosis and treatment plan [20]. As information brokers, nurses provide information to the health care team about children and families both before and after discussions about advanced care planning, provide detailed information about the treatment to children and families, answer additional questions from children and parents and clarify all misconceptions, and also organize discussions amongst the family and the health care team and reviews the topics discussed in the previous discussion regarding the care plan [21, 24].

As an advocate, the nurse may convey the clients' needs and expectations to other health professionals, such as communicating the clients' views on information provided by the physician. Communication at the end-of-life care, which already began when a serious diagnosis had to be discussed and bad news delivered to a child and his or her parents can be burdensome as it is often related to further uncertainties, moreover the inadequacy of professional and personal support for child and parent [18]. The nurse, as an informer, has to communicate family members the things they need to ask the physician [25]. Nurses also help clients get their rights and help families in making decisions. As an advocate for the family, the nurse should provide clear information and explain the implications of the decisions taken; for example, in decision making related to DNR, a nurse should explain the DNR as well as the implications until the family really understands before making a decision [8]. Although parents may not always 
be contented with how the healthcare team reveals the diagnostic information [26], parents want the physicians to discuss the options of advance care and to support them in complex decision making, even though nurses might not precede the discussions, but they shall be influential in advocating for discussions to take place and that patient preferences are expressed [21].

Another role of the nurse is as an educator. Based on the results, nurses provide health education to children and parents about care and reiterate the doctor's explanation about treatment program. Nurses have to interpret what physicians have said and also translate medical terms in order to make the families understand; this is where a nurse becomes an informer $[27,28]$. Nurses also have to provide health education during discharge, planning for sustainable care at home. A nurse could be the finest member of the healthcare team to assess family comprehension and provide clarification regarding the given information [29]. In order to enhance the care of dying patients and family, better education and good communication are needed regarding terminal care with support from staff [25].

Based on the results of the study, while providing care to terminally ill children, as an information broker, nurses provide direct care to patients with good communication and provide detailed information related to nursing interventions. Parents require the health care team to discuss the options of an advance care plan and to help parents in complex decision making [21]. As a health care provider, nurses help each individual achieve their optimal welfare [6]. Provision of care to patients with terminal conditions includes physical, psychosocial, developmental, cultural, and spiritual care.

As an informer, performing the above roles for children with a terminal illness is an extraordinary challenge for nurses. Nurses must be able to become good information brokers by overcoming possible barriers. Nurses must also be able to improve their communication skills. Furthermore, to identify palliative care need for child and family, the health care team must be trained to enhance communication among them. In this way the incidence of conflict and moral distress will be alleviated [23]. In addition, to be able to help nurses as information brokers, it would be beneficial to develop and provide digital information such as a brochure or a poster that contains explanations regarding common issues related to treatment for children with a terminal illness or answers to frequently asked questions (FAQs) that can be identified through surveys of patients, their parents as well as practitioners.

\section{CONCLUSION}

To conclude, nurses play several important roles in children's life with a terminal illness. These roles include them being a communicator, a counselor, a collaborator, an educator, and as a care provider. While performing the roles, the nurse becomes an information broker for terminally ill children and their families. Therefore, nurses must acquire good communication skills and also the knowledge related to the condition of the child and the ability to work with other health care teams with the aim of providing holistic and comprehensive care to children with a terminal illness.

\section{ETHICS APPROVAL AND CONSENT TO PARTI- CIPATE}

This study is approved by the ethical committee on health research RSUP Dr. Hasan Sadikin Bandung, Indonesia with approval number LB.04.01/A05/EC/191/VII/2017.

\section{HUMAN AND ANIMAL RIGHTS}

Not applicable.

\section{CONSENT FOR PUBLICATION}

Informed consent was obtained from all participants.

\section{AVAILABILITY OF DATA AND MATERIALS}

Not applicable.

\section{FUNDING}

This research was supported by an internal grant from Universitas Padjadjaran.

\section{CONFLICT OF INTEREST}

The authors declare no conflict of interest, financial or otherwise.

\section{ACKNOWLEDGEMENTS}

The authors are thankful for the contributions of the nurses as respondents in this study. The authors also express gratitude to Neti Juniarti, Ph.D., and Professor Suryani for giving suggestions on this research.

\section{REFERENCES}

[1] Hockenberry MJ, Wilson D, Rodgers C. Wong's Essentials of Pediatric Nursing. 10 $0^{\text {th }}$ ed. Missouri: Elsevier 2017.

[2] Kyle T, Carman S. Essentials of pediatric nursing. $2^{\text {nd }}$ ed. USA: Wolters Kluwer Health, Lippincot Williams \& Wilkins 2013.

[3] Khraisat OM, Alakour NA, O'Neill TM. Pediatric end-of-life care barriers and facilitators: Perception of nursing professionals in Jordan. Indian J Palliat Care 2017; 23(2): 199-206.

[http://dx.doi.org/10.4103/0973-1075.204232] [PMID: 28503041]

[4] American Nurses Association. American nurses association position statement on nurses' roles and responsibilities in providing care and support at the end of life. ANA Position Statement 2016; 1-10.

[5] Berman A, Snyder S, Frandsen G. Kozier \& Erb's Fundamentals of Nursing: Concepts, Process, and Practice. $10^{\text {th }}$ ed. New Jersey: Pearson Education, Inc 2016.

[6] Rosdahl CB, Kowalski MT. Textbook of Basic Nursing. 10th ed. Philadelphia: Lippincott 2012.

[7] Docherty SL, Thaxton C, Allison C, et al. The nursing dimension of providing palliative care to children and adolescents with cancer. Clin Med Insights Pediatr 2012; 6: CMPed.S8208. [http://dx.doi.org/10.4137/CMPed.S8208]

[8] Adams JA, Bailey DE Jr, Anderson RA, Docherty SL. Nursing roles and strategies in end-of-life decision making in acute care: A systematic review of the literature. Nurs Res Pract 2011; 2011527834 [http://dx.doi.org/10.1155/2011/527834] [PMID: 21994831]

[9] Baran ML, Jones JE. Mixed methods research for improved scientific study. Hershey: Information Science Reference 2016. [http://dx.doi.org/10.4018/978-1-5225-0007-0]

[10] McHugh MD, Lake ET. Understanding clinical expertise: Nurse education, experience, and the hospital context. Res Nurs Health 2010; 33(4): 276-87.

[http://dx.doi.org/10.1002/nur.20388] [PMID: 20645420]

[11] Mayring P. 2014. Available at: https://www.psychopen.eu/fileadmin/ user upload/books/mayring/ssoar-2014-mayringQualitative_content_analysis_theoretical_foundation.pdf

[12] Erlingsson C, Brysiewicz $\bar{P}$. A hands-on guide to doing content 
analysis. Afr J Emerg Med 2017; 7(3): 93-9. [http://dx.doi.org/10.1016/j.afjem.2017.08.001] [PMID: 30456117]

[13] Bengtsson M. How to plan and perform a qualitative study using content analysis. NursingPlus Open 2016; 2: 8-14.

[http://dx.doi.org/10.1016/j.npls.2016.01.001]

[14] Cope DG. Methods and meanings: credibility and trustworthiness of qualitative research. Oncol Nurs Forum 2014; 41(1): 89-91. [http://dx.doi.org/10.1188/14.ONF.89-91] [PMID: 24368242]

[15] Graneheim UH, Lindgren BM, Lundman B. Methodological challenges in qualitative content analysis: A discussion paper. Nurse Educ Today 2017; 56: 29-34.

[http://dx.doi.org/10.1016/j.nedt.2017.06.002] [PMID: 28651100]

[16] Polit DF, Beck CT. Essentials of Nursing Research: Appraising Evidence for Nursing Practice. 9th ed. Philadelphia: Wolters Kluwer 2018.

[17] Akard TF, Hendricks-Ferguson VL, Gilmer MJ. Pediatric palliative care nursing. Ann Palliat Med 2019; 8(Suppl. 1): S39-48. [http://dx.doi.org/10.21037/apm.2018.06.01] [PMID: 30180727]

[18] Bergsträsser E, Cignacco E, Luck P. Health care professionals' experiences and needs when delivering end-of-life care to children : a qualitative study. Palliat Care 2017; 101178224217724770 [http://dx.doi.org/10.1177/1178224217724770] [PMID: 28835736]

[19] Suttle ML, Jenkins TL, Tamburro RF. End-of-life and bereavement care in pediatric intensive care units. Pediatr Clin North Am 2017; 64(5): 1167-83.

[http://dx.doi.org/10.1016/j.pcl.2017.06.012] [PMID: 28941542]

[20] Mani ZA. Intensive care unit nurses experiences of providing end of life care. Middle East J Nurs 2012; 10: 3-9. [http://dx.doi.org/10.5742/MEJN.2015.92778]

[21] Hockenberry MJ, Wilson D. Wong's Nursing Care of Infants and Children. $11^{\text {th }}$ ed. Missouri: Elsevier 2019.

[22] Isaacson MJ, Minton ME. End-of-life communication nurses cocreating the closing composition with patients and families. ANS Adv Nurs Sci 2018; 41(1): 2-17.

[http://dx.doi.org/10.1097/ANS.0000000000000186] [PMID 29389725]

23] Martin M. Missed opportunities: A case study of barriers to the delivery of palliative care on neonatal intensive care units. Int J Palliat Nurs 2013; 19(5): 251-6

[http://dx.doi.org/10.12968/ijpn.2013.19.5.251] [PMID: 23971309]

[24] Emanuel LL, Librach SL. Palliative Care: Core Skills and Clinical Competencies. $2^{\text {nd }}$ ed. Missouri: Saunders Elsevier 2011.

[http://dx.doi.org/10.1016/B978-1-4377-1619-1.00001-9]

[25] Espinosa L, Young A, Symes L, Haile B, Walsh T. ICU nurses' experiences in providing terminal care. Crit Care Nurs Q 2010; 33(3): 273-81.

[http://dx.doi.org/10.1097/CNQ.0b013e3181d91424] [PMID: 20551742]

[26] Coad J, Patel R, Murray S. Disclosing terminal diagnosis to children and their families: palliative professionals' communication barriers. Death Stud 2014; 38(1-5): 302-7.

[http://dx.doi.org/10.1080/07481187.2012.753555] [PMID: 24593008]

[27] Bushinski RL, Cummings KM. Practices of effective end-of-life communication between nurses and patients/families in two care settings. Creat Nurs 2007; 13(3): 9-12.

[http://dx.doi.org/10.1891/1078-4535.13.3.9] [PMID: 18286973]

[28] Calvin AO, Kite-Powell DM, Hickey JV. The neuroscience ICU nurse's perceptions about end-of-life care. J Neurosci Nurs 2007; 39(3): 143-50.

[http://dx.doi.org/10.1097/01376517-200706000-00004]

[PMID: 17591410

[29] Ranallo L. Improving the quality of end-of-life care in pediatric oncology patients through the early implementation of palliative care. J Pediatr Oncol Nurs 2017; 34(6): 374-80. [http://dx.doi.org/10.1177/1043454217713451] [PMID: 28602119]

\section{C) 2020 Adistie et al.}

This is an open access article distributed under the terms of the Creative Commons Attribution 4.0 International Public License (CC-BY 4.0), a copy of which is available at: https://creativecommons.org/licenses/by/4.0/legalcode. This license permits unrestricted use, distribution, and reproduction in any medium, provided the original author and source are credited. 